\title{
S2k Guidelines for Cutaneous Basal Cell Carcinoma - Part 2: Treatment, Prevention and Follow-up
}

Guidelines commissioned by the Dermatologic Cooperative Oncology Group, DeCOG (Arbeitsgemeinschaft Dermatologische Onkologie, ADO) of the German Cancer Society and the German Society of Dermatology (Deutsche Dermatologische Gesellschaft, DDG) ADO Guideline Coordinator: Prof. Dr. Stephan Grabbe, Mainz, Germany S2k Guidelines 032-021 "Basal Cell Carcinoma” (Update 2017/18)
Berenice M. Lang', Panagiotis Balermpas², Andrea Bauer ${ }^{3}$, Andreas Blum ${ }^{4}$, G. Felix Brölsch ${ }^{5}$, Thomas Dirschka ${ }^{6,7}$, Markus Follmann ${ }^{8}$, Jorge Frank ${ }^{9}$, Bernhard Frerich ${ }^{10}$, Klaus Fritz ${ }^{11}$, Axel Hauschild ${ }^{12}$, Ludwig M. Heindl' ${ }^{33}$, Hans-Peter Howaldt ${ }^{14}$, Stephan Ihrler ${ }^{15}$, Vinodh Kakkassery ${ }^{16,}{ }^{17}$, Bernhard Klumpp ${ }^{18,19}$, Albrecht Krause-Bergmann ${ }^{20}$, Christoph Löser ${ }^{21}$, Markus Meissner ${ }^{22}$, Michael M. Sachse ${ }^{23}$, Max Schlaak ${ }^{24}$, Michael P. Schön9, Lutz Tischendorf ${ }^{25}$, Michael Tronnier ${ }^{26}$, Dirk Vordermark ${ }^{27}$, Julia Welzel $^{28}$, Michael Weichenthal ${ }^{22}$, Susanne Wiegand ${ }^{29}$, Roland Kaufmann'22, Stephan Grabbe'

(1) Department of Dermatology, Mainz University Medical Center, Mainz, Germany

(2) Department of Radiation Oncology, Frankfurt University Medical Center, Frankfurt, Germany

(3) Department of Dermatology, Carl Gustav Carus University Medical Center, Dresden, Germany

(4) Dermatology and Teaching Practice, Konstanz, Germany

(5) Department of Plastic, Aesthetic, Hand and Reconstructive Surgery, Hanover Medical School, Hanover, Germany

(6) CentroDerm Clinic, Wuppertal, Germany

(7) Faculty of Health, Witten-Herdecke University, Witten, Germany

(8) German Cancer Society, Berlin, Germany

(9) Department of Dermatology, Venereology and Allergology, Göttingen University Medical Center, Göttingen, Germany

(10) Department of Oral and Maxillofacial Plastic Surgery, Rostock University Medical Center, Rostock, Germany

(11) Dermatology and Laser Center, Landau, Germany

(12) Department of Dermatology, Venereology and Allergology, Schleswig-Holstein University Medical Center, Kiel, Germany

(13) Department of Ophthalmology, Cologne University Medical Center, Cologne, Germany

(14) Department of Oral and Maxillofacial Surgery, Gießen University Medical Center, Gießen, Germany

(15) Laboratory for Dermatohistology and Oral Pathology, Munich, Germany

(16) Department of Ophthalmology, Schleswig-Holstein University Medical Center, Lübeck, Germany

(17) Department of Ophthalmology, Rostock University Medical Center, Rostock, Germany

(18) Department of Diagnostic and Interventional Radiology, Tübingen University Medical Center, Tübingen, Germany 
(19) Department of Radiology, Rems-Murr Medical Center, Winnenden, Germany

(20) Department of Plastic and Aesthetic Surgery, Gütersloh Medical Center, Germany

(21) Department of Dermatology, Ludwigshafen Medical Center, Ludwigshafen,

Germany

(22) Department of Dermatology, Venereology and Allergology, Frankfurt University Medical Center, Frankfurt, Germany

(23) Department of Dermatology, Allergology and Phlebology, Bremerhaven Medical Center, Bremerhaven, Germany

(24) Department of Dermatology and Allergology, Munich University Medical

Center, Munich, Germany

(25) Oral and Maxillofacial Surgery Practice, Halle, Germany

(26) Department of Dermatology, Venereology and Allergology, Helios Medical

Center, Hildesheim, Germany

(27) Department of Radiation Oncology, Halle University Medical Center, Martin

Luther University, Halle, Germany

(28) Department of Dermatology and Allergology, Augsburg Medical Center,

Augsburg, Germany

(29) Department of Otolaryngology, Leipzig University Medical Center, Leipzig,

Germany

\section{Summary}

Basal cell carcinoma (BCC) is the most common malignant tumor among fair-skinned individuals, and its incidence had been steadily rising in the past decades. In order to maintain the highest quality of patient care possible, the German S2k guidelines were updated following a systematic literature search and with the participation of all professional societies and associations involved in the management of the disease. Part 2 addresses issues such as proper risk stratification, the various therapeutic approaches, and prevention as well as follow-up of patients with basal cell carcinoma.

\section{Terminology}

"Locally advanced" basal cell carcinomas comprise a subgroup of tumors that require an interdisciplinary therapeutic concept due to their extent and in particular because of their destructive infiltrative growth. The hallmark of these tumors is that - following clinical diagnosis, primary excision for diagnostic confirmation or unsuccessful re-excision, and obtaining interdisciplinary expertise esp. in the field of surgery (tumor board) complete (Ro) resection cannot be definitively achieved due to factors such as involvement of vital or functionally important structures.

The definition of contraindication in this guideline also includes the patient's explicit request not to undergo surgery after the informed consent discussion (informed decision making).

\section{Risk stratification}

Given their locally destructive and usually non-metastatic growth pattern, staging of BCCs according to the TNM classification usually plays no clinical role ( $\mathrm{T}$ classification is too nonspecific, $\mathrm{N}$ and $\mathrm{M}$ status is negative in more than $99 \%$ of cases). Herein, we therefore present a method of risk stratification for assessing the likelihood of recurrence, which is intended to be a useful tool in the subsequent selection of treatment options.

\begin{tabular}{l} 
Statement (strong consensus) \\
\hline $\begin{array}{l}\text { Facial lesions - on and around the nose, eyelids and ears } \\
\text { in particular - are characterized by higher recurrence } \\
\text { rates than those in other sites. }\end{array}$ \\
Recommendation (strong consensus) \\
Risk stratification shall be included in the treatment \\
planning (Figure 1).
\end{tabular}


The following factors are relevant for the likelibood of recurrence of $\mathrm{BCC}[1]$ :

Site

A number of studies have shown that tumor development in the head/neck region, in particular the central face, is an independent risk factor for recurrence. This had led to the concept of classifying BCCs according to "risk zones" [2-4]. The "H zone" - areas with a high recurrence risk - includes the nose, eyelids/eyebrows/ periorbital region, lips, jaw angles, temples and ears/ periauricular region as well as the genitals, hands and feet. The "M zone" - areas with a moderate recurrence risk - includes the remaining face and scalp regions (cheek, forehead, scalp) as well as the neck and pretibial region. The trunk and extremities are considered to be "L zones" - areas with a low recurrence risk. The pre- auricular region as well as the forehead, temples, and nose are marked by an increased incidence of sclerosing BCC [5].

\section{Maximum tumor diameter}

Apart from the tumor site, the recurrence risk of BCC is also determined by the maximum clinical tumor diameter (Table 1) [4, 6]. The cut-offs given in Table 1 are based on retrospective analyses showing that recurrence in the $\mathrm{H}$ zone is more likely for tumors larger than $6 \mathrm{~mm}$ and in the $\mathrm{M}$ zone for tumors larger than $10 \mathrm{~mm}$ [7]. Studies by Breuninger and Dietz have provided clear evidence of a positive correlation between the horizontal tumor diameter and the likelihood of subclinical tumor residuals at a defined distance from the macroscopic tumor margins. If no margin-controlled excision is performed, surgical margins of $3 \mathrm{~mm}$ carry a

\section{Treatment algorithm for basal cell carcinoma (BCC)}

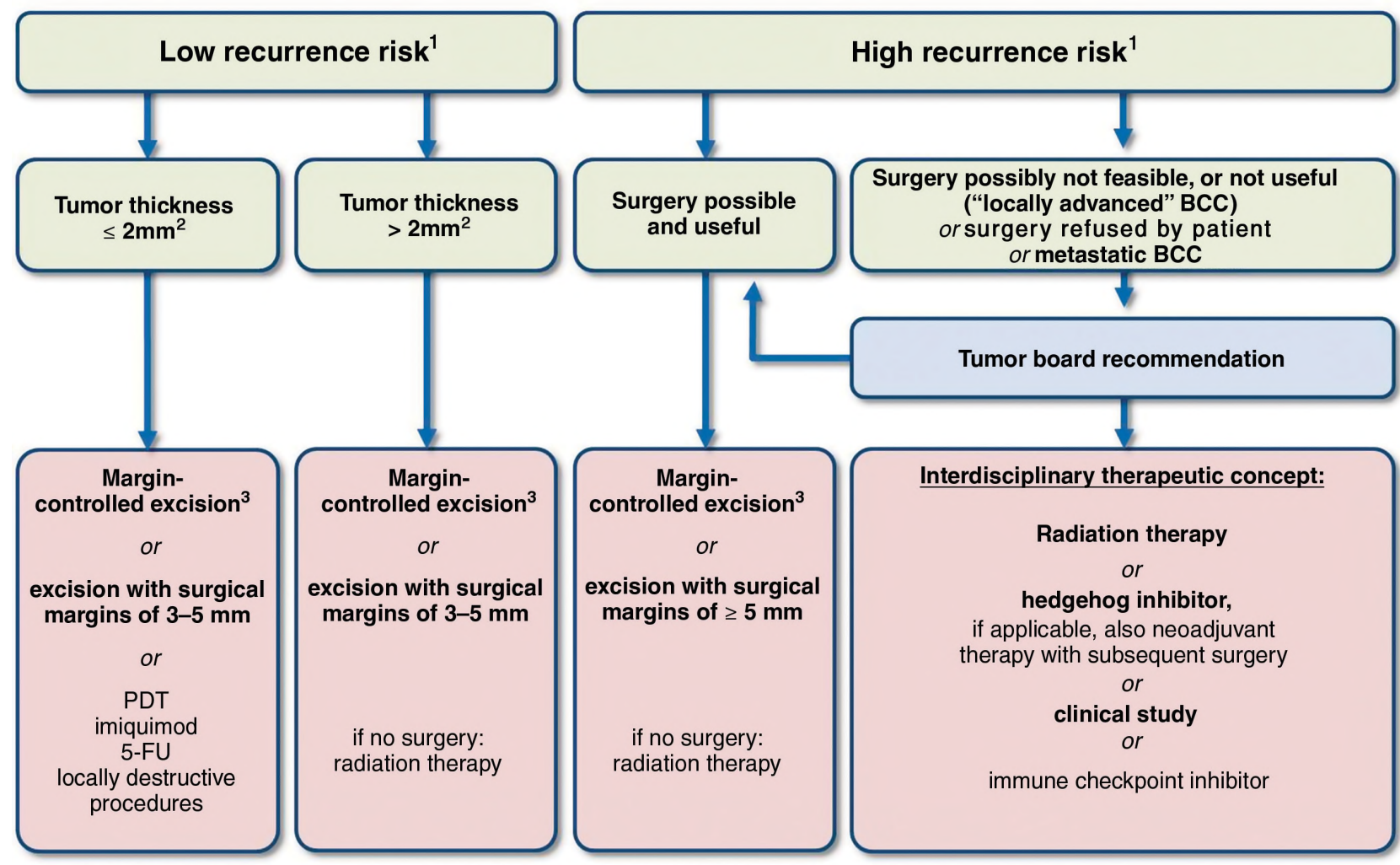

Bold font: strong recommendation, regular font: conditional or open recommendation

${ }^{1}$ See Table 1

${ }^{2}$ There is insufficient evidence for a cutoff regarding tumor thickness. The value given is based on interdisciplinary consensus and should therefore be considered a guideline and not a fixed value.

${ }^{3}$ Whenever feasible, "margin-controlled excision" is generally considered to be first-line therapy.

Figure 1 Treatment algorithm for basal cell carcinoma [6, 15-18]. 
Table 1 Classification of the various levels of recurrence risk in basal cell carcinoma (modified after [6]).

\begin{tabular}{|c|c|c|}
\hline & High recurrence risk* & Low recurrence risk \\
\hline Horizontal tumor diameter and site & $\begin{array}{l}- \text { H zone }^{* *} \geq 6 \mathrm{~mm} \\
- \text { M zone }^{* *} \geq 10 \mathrm{~mm} \\
- \text { L zone }^{* *} \geq 20 \mathrm{~mm}\end{array}$ & $\begin{array}{l}-\mathrm{H} \text { zone }<6 \mathrm{~mm} \\
-\mathrm{M} \text { zone }<10 \mathrm{~mm} \\
-\mathrm{L} \text { zone }<20 \mathrm{~mm}\end{array}$ \\
\hline Borders & Poorly defined & Well-defined \\
\hline Local recurrence & Yes & No \\
\hline (Histological) subtype & $\begin{array}{l}\text { - sclerosing } \\
\text { - infiltrative } \\
\text { - metatypical } \\
\text { - micronodular }\end{array}$ & $\begin{array}{l}\text { - superficial } \\
\text { - nodular } \\
\text { - adenoid } \\
\text { - trabecular } \\
\text { - infundibulocystic } \\
\text { - cystic } \\
\text { - fibroepithelial (Pinkus tumor) }\end{array}$ \\
\hline Tumor on chronic radiodermatitis & Yes & No \\
\hline Perineural growth & Yes & No \\
\hline \multicolumn{3}{|c|}{$\begin{array}{l}\text { *Presence of one of these factors results in classification in this category. } \\
{ }^{* *} \text { H zone: "central" face - eyelids, eyebrows, periorbital region, nose, up } \\
\text { ears, temples, genitals, hands, feet. } \\
\text { M zone: cheeks, forehead, chin, lower lip, scalp, neck, pretibial region. } \\
\text { L zone: trunk, extremities. }\end{array}$} \\
\hline
\end{tabular}

risk for $\mathrm{R} 1$ resection of $6 \%$ in BCCs with a tumor diameter of $<5 \mathrm{~mm}$; the risk may increase to almost $30 \%$ and $45 \%$ for tumor diameters of $10 \mathrm{~mm}$ and $>20 \mathrm{~mm}$, respectively [8].

\section{Recurrence}

The risk for another local recurrence is increased if there is already a history of prior recurrence, compared to previously untreated cases of primary BCC [7, 9, 10].

> Tumors arising on chronic radiodermatitis

Patients who have received radiation therapy with ionizing radiation in the past have a higher risk of developing BCC in the area previously irradiated. In addition, such tumors have an increased risk of recurrence $[11,12]$.

\section{Histological subtype}

See Table 1.

Immunosuppressed patients and those with a genetic syndrome are at greater risk of experiencing secondary tumors. Immunosuppression is associated with a 4- to 7-fold increased risk of developing BCC [13]. Unlike squamous cell carcinomas, BCCs occurring in organ transplant recipients are not characterized by greater aggressiveness [14].

\section{Surgical treatment}

Recommendation (strong consensus)
$\begin{aligned} & \text { Complete surgical removal with histological control of } \\ & \text { excision margins is the most effective treatment for BCC } \\ & \text { and shall be offered to patients as first-line therapy. }\end{aligned}$
Recommendation (strong consensus)
Depending on the recurrence risk, surgery may be per-
formed either as microscopically controlled surgery or
using individualized surgical margins and conventional
histology; for superficial variants, horizontal excision
(shave excision) with conventional histology may be
used.

Recommendations (strong consensus)

If conventional excision is used, surgical margins of 3 to $5 \mathrm{~mm}$ should be chosen for BCCs with a low recurrence risk.

For BCCs with a high recurrence risk and recurrent tumors, microscopically controlled surgery shall be performed. If possible, this should include complete examination of lateral and deep margins. Otherwise, conventional excision with surgical margins of $>5 \mathrm{~mm}$ should be performed. 


\section{(strong consensus)}

The objective of surgical treatment for BCC is the histologically complete removal, including all subclinical residuals (both laterally and towards the base) as well as functionally and aesthetically adequate reconstruction.

More than $95 \%$ of all BCCs can be reliably and definitively treated by excision. With a 5 -year recurrence rate of $2 \%$ to $8 \%$, surgical removal is superior to non-histologically controlled topical procedures (literature review in $[19,20]$ ).

Surgical removal is performed either as conventional excision with surgical margins that need to be individually determined based on the recurrence risk (chapter "risk stratification") and conventional histological examination or as microscopically controlled surgery (systematic margin control to ensure tumor removal both laterally and towards the base). For superficial and smaller BCCs (especially on the trunk and extremities), shave excision may be considered and is associated with comparable cure rates [21].

Preoperative imaging techniques may help better determine ill-defined tumor margins, especially in case of recurrent lesions [22].

\section{1 Conventional surgery of BCC}

\section{Recommendation (strong consensus)}

First-line therapy for incompletely $\left(\mathrm{R}_{1}\right)$ excised $B C C s$ is re-excision. For incompletely $(\mathrm{R} 1)$ excised $B C C s$ with a low recurrence risk, non-surgical procedures may be offered, too.

Compared to complete, microscopically controlled excision, a higher percentage of R1 situations must be expected when using conventional surgery with surgical margins extending beyond the visible tumor borders followed by histological examination of random cross-sections. Depending on surgical margins and individual tumor-related risk factors (histological subtype), this figure may be as high as $35 \%$ [8]. It should be added, though, that the difference in recurrence rates between the procedures becomes increasingly small when treating small low-risk BCCs. Gulleth et al. showed in a meta-analysis including 89 publications with 10,261 patients and 16,066 low-risk nodular BCCs with a diameter of $<2 \mathrm{~cm}$ that conventional excision with surgical margins of $3 \mathrm{~mm}$ was likewise associated with a very low risk of recurrence [17]. Depending on the tumor-specific risk of local recurrence and/or residual tumor tissue, current guidelines in other countries recommend variable surgical margins of up to $5 \mathrm{~mm}$ for low-risk BCCs when using conventional surgery. Regarding high-risk BCCs, lateral margins may reach up to $15 \mathrm{~mm}$, with deep margins extending down to the adipose tissue; for such lesions on the nose, ears, or scalp, deep margins extend down to the underlying fascia, perichondrium, or periosteum [23, 24].

For tumors with a low recurrence risk, surgical margins of 3 to $5 \mathrm{~mm}$ should be used to prevent recurrence. Exceptions may be made for small, well-defined nodular BCC (nBCC) and pigmented BCC lesions. Here, complete removal is achieved in almost all cases with narrow surgical margins of 2 to $3 \mathrm{~mm}$ [25]. If microscopically controlled surgery is not available, tumors with a high recurrence risk (Table 1) should be removed using conventional excision with surgical margins of more than $5 \mathrm{~mm}$. Clinically and histologically determined resection margins may differ due to tissue shrinkage following its removal. Even though such differences are smaller in skin affected by aging and elastotic damage, shrinkage of the excised specimen of approximately $17 \%$ to $20 \%$ in length and $10 \%$ in width can be expected $[26,27]$. There is currently no data that would justify re-excision in the case of tumor-free margins if the surgical margins determined by histology are not as wide as initially planned clinically.

Conventional surgery has been reported to result in incomplete excisions in $4.7 \%$ to $24 \%$ of all surgically removed tumors; however, recurrence must be expected in only $26 \%$ to $41 \%$ of BCC lesions following incomplete excision. Moreover, approximately one-half of the specimens contain no residual tumor tissue following re-excision [19, 28-30]. There are, however, no reliable predictive indicators and recurrent tumors may exhibit a more aggressive growth pattern after incomplete excision [32]. Accordingly, re-excision shall be performed after incomplete surgical removal (R1 resection). In the event of high-risk tumors or lesions in critical sites as well as deep recurrences, re-excision should be preferably performed as microscopically controlled surgery to ensure complete tumor clearance [29, 33]. Alternatively, radiation therapy may be used for incompletely resected highrisk BCCs, especially if there are factors that complicate a subsequent surgical procedure (extent of the re-excision, comorbidity).

Non-surgical procedures may present an alternative for incompletely resected low-risk BCCs (imiquimod, photodynamic therapy [PDT], cryosurgery, laser, clinical follow-up). If non-surgical procedures (including mere clinical follow-up) are used, close clinical monitoring is required, including optical methods.

\section{2 Microscopically controlled surgery of BCC}

Microscopically controlled surgery refers to tissue-sparing surgical excision of a tumor with traceable markings and subsequent complete histopathological evaluation of lateral and deep margins. With this method, it is possible to 
determine the exact location of subclinical tumor spread and, if necessary, to perform targeted re-excision to ensure $\mathrm{R} 0$ resection. There are various modifications to this procedure [34]. While both frozen sections and paraffin sections may be used for tissue processing, the latter are of greater diagnostic significance.

The procedure is superior with respect to the frequency of recurrences. In a prospective, randomized study of highrisk facial tumors, the 10-year likelihood of recurrence was lower than for conventional surgery (for primary tumors [n $=408] 4.4 \%$ versus $12.2 \%, \mathrm{p}=0.100$; however, the difference was only significant for recurrent tumors [ $\mathrm{n}=204]$ $3.9 \%$ versus $13.5 \%, p=0.023$ ) [35]. In particular, microscopically controlled surgery is indicated for tumors associated with an increased likelihood of subclinical spread and recurrence $[34,36]$. This includes recurrent tumors with extensive subclinical spread [37] and a likelihood of renewed recurrence between 11.6 and $17.4 \%$ [9].

Apart from the higher risk of incomplete excision, conventional surgery with surgical margins may require unnecessarily extensive reconstructive surgery associated with functional and aesthetic impairment [38].

\section{3 Shave excision}

\section{Recommendation (strong consensus)}

In individual cases, shave excision may be used to treat small superficial BCCs on the trunk and extremities if there are contraindications for conventional surgery or other topical therapeutic options or in case of a larger number of lesions.

Tumor removal by shave excision allows for (limited) histological control and may therefore be considered in certain situations. Given the higher likelihood of residual tumor cells in the area treated, recurrence rates are increased, especially in the head/neck region, and may be as high as $83 \%$ for nBCC [39]. Better results, however, can be achieved for lesions on the trunk, in particular for superficial basal cell carcinoma (sBCC) $[21,40]$. The aesthetic outcome after shave excision is worse than for conventional surgery. It is essential that patients be informed about the subsequent scar formation beforehand.

\section{4 Surgical treatment of BCC on the eyelids}

\section{Recommendation (strong consensus)}

Given the anatomic site, BCC of the eyelids poses specific risks with respect to the functional integrity of the eye, eyelid, and lacrimal apparatus, which shall be considered during treatment planning.
The human eye is of utmost significance both as a sensory organ and as a means of social interaction. The eyelids provide a crucial protective function for the eyeball. Relevant aspects include voluntary lid closure, involuntary blinking (approximately 10,000 times per day), and facial nerve function. Any surgery aimed at treating a palpebral BCC therefore requires further preoperative considerations. In this context, treatment planning for BCCs with an increased risk of recurrence shall include considerations on how to manage potential ocular injuries. Prior to surgery of palpebral BCCs with an increased risk of recurrence, patients shall therefore be adequately informed about potential ocular injuries as well as potential disorders of the ocular surface (including subsequent defects due to impaired lid closure or lid deformities). The objective of surgical eyelid reconstruction is to maintain its protective function for the eye and to preserve or reconstruct the lacrimal apparatus (lacrimal gland as well as afferent and efferent tear ducts). Various options for eyelid reconstruction are presented, without claiming to be exhaustive [41]. Eyelid closure, eyelid position, eye surface as well as function of the lacrimal apparatus - if affected - shall be evaluated within the first three months after surgical treatment of BCC.

\section{5 Surgical approach for locally advanced tumors (IaBCC)}

\section{Recommendation (strong consensus)}

For locally advanced tumors, the treatment concept shall be determined by an interdisciplinary tumor board.

For laBCCs that are not definitively amenable to R0 resection, the feasibility of a surgical procedure shall be reviewed. Not only does this apply to a curative approach but also to palliative indications or to a neoadjuvant approach following the use of hedgehog signaling pathway inhibitors to reduce tumor volume. Prior to surgery, an interdisciplinary tumor board shall determine the appropriate treatment strategy and the requirement for preoperative imaging studies [24, 42].

\section{Radiation therapy}

Recommendation (strong consensus)
For locally advanced BCCs that are not amenable to
complete local resection due to size, site, age, or the pa-
tient's comorbidity, the indication for radiation therapy
shall be reviewed by an interdisciplinary
board.

Recommendation (consensus)

Radiation therapy may be offered for the treatment of $\mathrm{BCC}$ if there are contraindications for surgery. 


\section{(strong consensus)}

Radiation therapy shall not be used in patients with syndromes and autoimmune disorders that are associated with increased sensitivity to radiation (such as basal cell carcinoma syndrome, xeroderma pigmentosum, lupus erythematosus, scleroderma).

While surgical treatment is the gold standard of local BCC therapy, certain tumor features (size, infiltration of deep structures, sites associated with mutilating surgery), comorbidity, or patient preference may result in choosing a non-surgical procedure. Multiple publications (case series, retrospective studies, reviews) have shown clinical control rates of $92 \%$ to $99 \%$ for smaller BCCs and $70 \%$ to $90 \%$ for high-risk BCCs (large size, high-risk sites, or recurrence) (follow-up period between four months and ten years) for various types of radiation therapy (predominantly brachytherapy, but also electron and orthovoltage radiation therapy) [9, 43-51]. The only randomized study $(n=347)$ that compared surgery and radiation therapy (1: 1 randomization) showed surgery to be significantly superior in terms of local disease control, with $99.3 \%$ versus $92.5 \%$ after 4 years (maximum follow-up period) [52]. However, the radiation doses and fractionation schedules used in that study were quite different compared to modern standards and thus somewhat inadequate.

The side effects of radiation therapy are relatively low. As regards the aesthetic outcome, a review of the literature revealed that more than $90 \%$ of patients surveyed using a questionnaire rated the aesthetic outcome as "good" or "excellent" [53]. Moreover, there is evidence that the aesthetic outcome depends on the single dose. The following results were achieved with conventionally fractionated or moderately hypofractionated radiation therapy (1.8 to $3 \mathrm{~Gy})$ : 19 fractions of 3 Gy each, 94 \% "excellent" or "good" [54]; hypofractionated regimen with three fractions of $10.2 \mathrm{~Gy}$ each, $48 \%$ "good", $50 \%$ “acceptable", 2 \% "poor" [55].

When deliberating the indication for radiation therapy, it is important to consider the patient's life expectancy in relation to the risk of developing radiation-induced secondary malignancies [56]. Given that the latency period for the development of secondary cutaneous malignancies is at least ten years, this puts the risk for patients above the age of 70 (mean age at the time of BCC diagnosis) into perspective [57-59].

Although the various types of radiation therapy have not been compared directly, the comparable results obtained in the aforementioned case series suggest that high-energy electrons (4 to $10 \mathrm{MeV}$ ), HDR brachytherapy, orthovoltage (100 to $200 \mathrm{kV}$ ) or low-voltage irradiation (10 to $50 \mathrm{kV}$ ) may be similarly effective. Schulte et al. reported on a total of 1,300 tumors treated with low-voltage (soft) X-rays $(94.9 \%$ clinical tumor clearance with a mean follow-up period of 77 months) [60]. However, extreme caution is required for deeply infiltrating lesions as low-voltage (soft) X-rays in particular are disadvantageous in terms of tumor control due to their low depth of penetration and efficacy (beyond $5 \mathrm{~mm}$ tumor depth, there is $<90 \%$ of the physical dose [energy of $50 \mathrm{kV}$ ], with exponential decrease towards deeper layers) [43-51]. The total dose for normofractionated regimens (five fractions of 2 Gy each per week) should be at least $60 \mathrm{~Gy}$; for larger lesions ( $>2 \mathrm{~cm}$ horizontal diameter), the dose may be increased to 66 Gy. Very old patients may be offered moderately hypofractionated (five fractions of $2.5 \mathrm{~Gy} /$ week up to a total dose of $55 \mathrm{~Gy}$; five fractions of $3 \mathrm{~Gy} /$ week up to $57 \mathrm{~Gy}$ ) or highly hypofractionated regimens ( 5 to 6 Gy twice per week up to a total dose of $60 \mathrm{~Gy})[6,45]$.

There is only little data comparing radiation therapy with other non-surgical local procedures, such as cryosurgery or imiquimod. In 1986, Hall et al. showed in a prospective, randomized trial that, two years post treatment, the clinical recurrence rate was $4 \%$ for radiation therapy compared to $39 \%$ for cryosurgery [61]. Furthermore, a small prospective, randomized controlled trial of 27 patients with palpebral BCC showed equal control rates, with better tolerability of irradiation compared with imiquimod in this region [62].

Incomplete resection (R1, R2) or perineural growth is associated with high local recurrence rates [63-65]. Although there is no prospective randomized data, it appears obvious that postoperative radiation therapy may improve local tumor control [66-68]. Retrospective data from a group of 33 patients with incompletely resected BCC of the medial canthus region showed a local control rate of $100 \%$ for patients with positive margins in this high-risk location [69].

Patients unsuitable for radiation therapy include individuals at high risk for the induction of secondary tumors (age $<40$, patients with basal cell carcinoma syndrome or other genetic syndromes) as well as patients with connective tissue diseases who are at an increased risk for above-average acute toxicity (lupus erythematosus, scleroderma).

\section{Topical treatment}

\section{1 Topical agents}

Various topical therapies are used in the treatment of lowrisk BCCs and BCCs that occur in special settings, especially in multimorbid elderly patients. The benefits of these agents include, in particular, the possibility of home application, the preservation of surrounding tissue, and a good cosmetic outcome with avoidance of scar formation [19]. In addition, topical agents are important options for patients with multiple (superficial) BCCs. 


\section{1. 1 Imiquimod}

\section{Recommendation (strong consensus)}

Imiquimod $5 \%$ cream may be used for the treatment of superficial BCC, primarily if there are contraindications for surgery.

Imiquimod is a toll-like receptor agonist (TLR7 and 8) that can activate both innate and cellular immune responses through induction of proinflammatory cytokines and other mediators. This effect results in targeted killing of tumor cells. Imiquimod $5 \%$ cream is applied once daily on five days per week for a total of six weeks. Before going to bed, a thin layer of cream should be applied to the area to be treated and $1 \mathrm{~cm}$ of the surrounding skin; the cream should be left on for eight hours. In the EU, imiquimod it is currently approved for the treatment of sBCC with a diameter of less than $2 \mathrm{~cm}$ in immunocompetent adults [70].

Various studies have shown a tumor clearance of $43 \%$ to $100 \%$ for sBCC [71]. A study of 501 patients comparing surgery and imiquimod showed surgery to be superior, with tumor clearance of $98 \%$ after three years compared to $84 \%$ in the imiquimod group (relative risk [RR] 0.84, $98 \%$ confidence interval [CI] 0.78-0.91; $\mathrm{p}<0.0001)$. Approximately one-third of the tumors were located on the face and one-third on the trunk. Clinical follow-up after five years showed similar results [72, 73]. Another study of 601 patients compared MALPDT with imiquimod and 5-FU. After three years, tumor clearance was $80 \%$ in the imiquimod group (95\% CI 71.6-85.7); $58 \%$ in the MAL-PDT group (95\% CI 47.8-66.9); and $68 \%$ in the 5-FU group (95\% CI 58.1-76.3). Approximately $60 \%$ of BCCs were located on the trunk [74].

In summary, the majority of studies show that imiquimod is especially useful for the treatment of sBCC in low-risk locations. Potential adverse effects include an inflammatory reaction in the application area characterized by erythema, swelling, scaling, blistering, and pain. It has been demonstrated that there is a correlation between the severity of this inflammatory reaction and the clinical response [70]. Imiquimod may also cause flu-like symptoms and localized lymphadenopathy.

\section{1. 2 5-Fluorouracil}

Recommendation (strong consensus)
5-Fluorouracil may be used for the treatment of superficial
BCC, primarily if there are contraindications for surgery.

5-Fluorouracil (5-FU) is approved for topical treatment of sBCC, if surgical procedures have been unsuccessful or are not feasible. It is applied twice daily for four weeks at a concentration of $5 \%$. In a recent comparative study between MAL-PDT, imiquimod, and 5-FU, Arits et al. showed 5-FU to be similarly effective in treating sBCC as MAL-PDT but inferior to imiquimod (tumor clearance after twelve months: $72.8 \%$ [95 \% CI 66.8-79.4] for MAL-PDT; $83.4 \%$ [78.288.9] for imiquimod; $80.1 \%$ [74.7-85.9] for 5-FU) [75]. The three-year follow-up data of the same study revealed similar results (tumor clearance after 36 months: $58.0 \%$ for MALPDT (95 \% CI 47.8-66.9); $79.7 \%$ for imiquimod $(95 \% \mathrm{CI}$ 71.6-85.7); 68.2 \% for 5-FU (95\%-CI 58.1-76.3) [74]. Adverse effects primarily include an inflammatory reaction in the application area, which may be associated with erythema, swelling, scaling, blistering and even ulceration as well as pain.

In addition to its topical use, intralesional injection of 5-FU is also feasible, albeit not approved in Germany. A recent review article reported data on intralesional 5-FU therapy from eight studies with a total of 140 tumors. The histological and clinical response rates for sBCC and nBCC ranged from $79 \%$ to $100 \%$. However, given that the relevant studies were quite old and included only small cohorts, it is not possible to issue a recommendation [76].

\section{1. 3 Ingenol mebutate}

Recommendation (strong consensus)
Given the lack of sufficient data, ingenol mebutate can-
not be recommended for the treatment of BCC.

Ingenol mebutate is successfully used in the treatment of actinic keratoses and only approved for this indication. While data from phase $1 / 2$ studies provides evidence of its effectiveness in treating BCC, there have been no published phase 3 studies. Using various treatment regimens, phase 1/2 studies have shown histological evidence of tumor clearance in $38 \%$ to $63 \%$ of BCCs thus treated [77, 78]. Potential adverse effects include an inflammatory reaction in the application area characterized by erythema, swelling, scaling, blistering, and pain, which are due to the agent's mechanism of action.

\section{1. 4 Diclofenac}

Recommendation (strong consensus)
Given the lack of sufficient data, diclofenac cannot be
recommended for the treatment of BCC.

NSAIDs may interfere via different routes with the signaling pathways that result in BCC development, for example by inhibition of cyclooxygenase 2 (COX2). In a phase 2 study, it was shown that topical application of 
diclofenac $3 \%$ (under occlusion) twice daily for eight weeks resulted in a histologically confirmed tumor clearance rate of $64 \%$ for sBCC. No effect was observed in the treatment of nBCC [79].

\section{2 Photodynamic therapy}

(strong consensus)

Photodynamic therapy (with 5-ALA or MAL) may be used for the treatment of thin BCCs, primarily if there are contraindications for surgery.

Photodynamic therapy (PDT) involves the topical application of certain agents (5-aminolevulinic acid [5-ALA] and its ester methyl aminolevulinate [MAL]) that are subsequently converted to a photosensitizer (protoporphyrin IX, PPIX) within the tumor tissue. This is followed by irradiation with red light whose wavelength (570-670 nm) lies within the absorption spectrum of the photosensitizer. Activation of PPIX subsequently results in intracellular generation of singlet oxygen, which causes the destruction of tumor cells. This form of treatment is largely selective for tumor tissue and has to be performed twice per treatment cycle. In Germany, several substances are approved for the treatment of sBCC and nBCC: MAL and a nanoemulsion containing ALA. Prior to treatment, it is recommended to remove scabs and degrease the area to be treated.

There have been multiple randomized trials investigating PDT in the management of BCC. Using MAL-PDT, a cure rate of $92 \%$ to $97 \%$ was demonstrated for $s B C C$, with a recurrence rate of $9 \%$ after one year [80, 81]. A review of all available studies from 1990-1995 showed that ALA-PDT too was associated with cure rates of up to $89 \%$ in patients with sBCC [82]. In a retrospective case series and cohort study of 323 patients, predictors of recurrence included lesions in the head and neck region as well as tumor size $>10 \mathrm{~mm}$ [83].

In patients with $n B C C$, MAL-PDT achieved cure rates of $91 \%$, with $76 \%$ of the patients still tumor free after five years. Remarkably, most recurrences occurred within the first three years. In direct comparison, PDT was shown to be inferior to surgery in terms of recurrence rates (recurrence rate of $14 \%$ vs. $4 \%$ after five years) [84, 85]. Another study was able to demonstrate that $\mathrm{nBCC}$ and lesions on the extremities were predictors of a poor response to MAL-PDT, with a tumor clearance rate of $33 \%$ for $\mathrm{nBCC}$ and $82 \%$ for sBCC [86]. Based on a 2016 meta-analysis that included 596 nBCCs from five randomized controlled trials, MAL-PDT was associated with a $79 \%$ tumor clearance after five years [87]. Prior removal of scabs appears to be particularly important when treating nBCCs and should therefore be part of the procedure [88]. A major limitation of most studies published to date is the fact that tumor thickness (depth of penetration) was not taken into account. Especially in the case of nBCC, however, tumor thickness plays an important role in terms of the risk of recurrence. As a general rule, only thin tumors should be treated with PDT. There is, however, insufficient evidence to determine a cutoff in this regard.

Only conventional PDT is approved for the treatment of BCC, that is PDT using a red lamp (wavelength around $635 \mathrm{~nm}$ ). There have also been initial studies on the use of daylight-PDT with natural light. In an open, uncontrolled, prospective explorative study of 21 patients and a total of 32 tumors, two sessions within one week resulted in a tumor clearance rate of $74 \%$ after one year [89]. In this context, it will be necessary to obtain data from larger studies that also include histological evaluation.

Advantages of PDT include the good or even very good aesthetic outcome and the fact that it can be performed on an outpatient basis. Moreover, treating immunosuppressed patients is also possible $[90,91]$. The most significant downside is the pain associated with the procedure. Analgesia using local anesthesia (but not topical analgesics) or cold air may be useful. Post-treatment sequelae may include erythema with or without edema as well as erosions and scabs, which resolve after two to six weeks.

\section{3 Cryosurgery}

Recommendation (strong consensus)
cryosurgery may be used for the treatment of small
contraindications for surgery or topical therapies.

In cryosurgery, liquid nitrogen is used to induce non-selective cell necrosis. Two treatment methods are available: the contact technique and the open-spray technique; both use temperatures of $-196^{\circ} \mathrm{C}$. There is usually no histological evaluation. Removing tumor tissue prior to treatment may improve the prospect of success. The procedure has not yet been standardized. Cryosurgery may be an alternative to surgery, especially for elderly patients with small and multiple sBCCs on the trunk and extremities [92]. In a prospective study (1986) that compared cryosurgery and radiation therapy in 93 patients, the clinical recurrence rate after two years was $4 \%$ in the group receiving radiation therapy and $39 \%$ after cryosurgery [61]. In a 2016 study, eight elderly patients (> 60 years of age) with sBCC of the lower extremities were treated with intralesional cryosurgery. Here, a probe is used to introduce liquid nitrogen directly into the tumor tissue. Histological examination demonstrated a clearance rate of 
$100 \%$ [93]. Larger patient groups are needed to confirm the role of intralesional cryosurgery, especially in elderly individuals.

\section{4 Laser therapy}

Recommendation (strong consensus)
Ablative ( $\mathrm{CO}_{2}$, erbium:YAG) and non-ablative (dye,
$\mathrm{Nd}$ :YAG) lasers may be used in the treatment of low-risk
BCC if there are contraindications for surgery or topical
therapies.

\section{4. 1 Ablative laser therapy}

$\mathrm{CO}_{2}$ and erbium:YAG lasers may be used in the treatment of low-risk BCC. Studies have shown that, depending on the chosen parameters, both lasers achieve similarly good therapeutic results in terms of the depth of ablation and thermal coagulation as well as aesthetic outcome [94]. While the widespread use of lasers has been hampered by the fact that this method does not allow for histological evaluation, modern imaging techniques may be useful in this regard. In patients previously treated with ablative lasers, Yung et al. showed that subclinical tumor spread tended to occur in deeper tissue layers rather than at the lateral margins [95]. Regular clinical follow-up after laser treatment is therefore indispensable.

\section{4. 2 Laser assisted drug delivery}

Ablative fractional lasers increase the uptake of topically applied therapeutic agents. Most studies have focused on the fact that pretreatment with ablative fractional lasers distinctly increases ALA- and MAL-induced fluorescence, thus improving the effectiveness of PDT in patients with BCC [96]. Nguyen et al. conducted a study on the safety and efficacy of ablative fractional laser-assisted topical 5-FU delivery in the treatment of sBCC, which showed histological evidence of tumor clearance in $71 \%$ of the cases [97].

\section{4. 3 Non-ablative laser techniques}

The effect of non-ablative dye lasers is based on selective occlusion of afferent vessels without causing damage to epidermis or dermis. A 2015 study examined dye laser therapy prospectively. Tumor clearance was achieved in $78 \%$ of sBCCs at low-risk sites; however, there was frequent dyspigmentation [98]. Clinical data is also available for the Nd:YAG laser (1,064 nm). In a study of 33 BCCs on the trunk and extremities, this method resulted in a histological clearance rate of $90 \%$; no scarring was observed $[99,100]$.

\section{Systemic treatment}

\section{Recommendation (strong consensus) \\ In case of locally advanced or metastatic BCC, treatment with a hedgehog inhibitor shall be discussed by an inter- disciplinary tumor board. Moreover, the possibility of in- cluding the patient in a clinical study shall be reviewed.}

Recommendation (strong consensus)

For multiple BCCs associated with basal cell carcinoma syndrome, treatment with hedgehog inhibitors shall be offered.

Recommendations (strong consensus)

In case of locally advanced BCC, neoadjuvant therapy with a hedgehog inhibitor may be discussed.

There have been only very few reports of metastatic basal cell carcinoma ( $\mathrm{mBCC}$ ) with actual histological evidence of metastases. The estimated incidence is between $0.0028 \%$ and $0.55 \%$ [101]. However, the number of mBCCs may be systematically underestimated, given that patients with BCC usually undergo no metastatic workup. Potential metastases may therefore not be detected.

In a systematic meta-analysis, all cases of $\mathrm{mBCC}(\mathrm{n}=172)$ published from 1970 to 2011 were reviewed in terms of prognosis and treatment. Among the 100 cases that met certain inclusion and exclusion criteria for this meta-analysis, $50 \%$ exhibited regional metastases and the other $50 \%$ distant metastases. Patients with distant metastases were younger (mean age: 58.0 years) than patients with regional metastases $(66.3$ years). Although treatment data was available for 93 of the 100 patients, specific outcomes were not reported. Most patients with distant metastases received chemotherapy (36.2\%), whereas surgery was the standard treatment most commonly used for regional metastases $(87.0 \%)$. Median survival of patients with distant metastases was 24 months, compared to 87 months for those with regional metastases. From the individual publications on $\mathrm{mBCC}$ it can be seen that - in analogy to metastatic squamous cell carcinoma - predominantly platinum-based chemotherapies were used before 2012. In general, remission rates were between $20 \%$ and $30 \%$, and remission was of short duration (2-3 months) [102].

\section{1 Hedgehog inhibitors}

In 2012, the approval (FDA and EMA) of two hedgehog inhibitors - specific inhibitors of Smoothened, which plays a key role in BCC development - ushered in a new era of systemic treatment. The hedgehog inhibitors had been used in trials of patients with mBCC and laBCC and subsequently been approved. It should be noted, though, that, prior to the 
vismodegib and sonidegib trials, there had been no clear criteria for the diagnosis of so-called laBCC. The criteria used in these studies -1) no indication for conventional surgery or radiation therapy (tumor board decision), 2) multiple lesions and 3) multiple prior treatments - have only been established in recent years. There is therefore no published data on other systemic therapies, such as chemotherapy, specifically for the treatment of this particular tumor entity.

Vismodegib is the first newly approved hedgehog inhibitor. In the approval study (ERIVANCE) that included 104 patients with laBCC and $\mathrm{mBCC}$, it showed remission rates of $48 \%$ (laBCC) and $33 \%$ (mBCC) as well as a median duration of response of 9.5 and 7.6 months, respectively [103]. The final update of the approval study published in 2017 showed remission rates of $48.5 \%$ for metastatic and $60.3 \%$ for locally advanced tumors 39 months after the end of the recruitment phase [104]. In the latter group, 20 patients experienced complete remission and 18 showed partial remission. Patients with mBCC only saw partial remission; there was no case of complete remission. The median duration of response was 14.8 months (mBCC) and 26.2 months (laBCC). Median overall survival was 33.4 months in the mBCC group and had not yet been reached in the laBCC cohort. There were no treatment-related fatalities. The majority of patients experienced the usual class-specific adverse effects such as muscle spasms, alopecia, fatigue, or weight loss, which resulted in discontinuation of treatment in approximately $30 \%$ of the patients. The results were confirmed by another international trial (STEVIE) [105]. An update of the STEVIE trial from October 2017 showed remission rates of $68.5 \%$ for laBCC and $36.9 \%$ for $\mathrm{mBCC}$ in 1,215 evaluable BCC patients from 36 nations. The side effect profile was nearly identical to the ERIVANCE study.

Vismodegib was also investigated in a phase 2 study of patients with basal cell carcinoma syndrome [106]. The longterm data now available shows that the 26 patients treated with vismodegib (150 mg/day) developed significantly fewer new surgically eligible BCCs compared to the placebo arm ( $\mathrm{n}=15$ ) [107]. In the majority of patients, vismodegib therapy was interrupted due to adverse events. A subgroup of study participants $(n=18)$ were given the opportunity to take the hedgehog inhibitor for a period of 36 months. Only 3 of the 18 patients $(17 \%)$ tolerated vismodegib continuously for the entire time. The majority of the remaining cases discontinued treatment due to adverse events. Unlike the results of the interim analysis, prolonged treatment with vismodegib for 16 to 18 months frequently caused severe and irreversible alopecia [106, 107]. Previous observations that had shown an increased incidence of squamous cell carcinoma were not confirmed in the aforementioned study [108]. Given the spectrum of drug-related adverse events on long-term treatment and the markedly lower drug resistance to hedgehog inhibitors compared to other BCC variants, intermittent therapy with vismodegib seems to be appropriate for this high-risk patient group [107, 109].

Sonedigib, the second hedgehog inhibitor approved, received market authorization in Germany in 2017. In the approval study (BOLT), it initially demonstrated a remission rate of $36 \%$ and an almost identical spectrum of adverse events as vismodegib at a dose of $200 \mathrm{mg}$ (for which it has now been approved) [110]. In the study update one year later, remission rates in the $200 \mathrm{mg}$ group were $57.6 \%$ (laBCC) and $7.7 \%$ (mBCC). By that time, 18 of the 94 laBCC patients in remission showed progressive disease or had died; more than $50 \%$ of the patients had been in remission for more than six months. In the most recent BOLT update from August 2017 [111], remission rates of $56.1 \%$ (central review process) and $71.2 \%$ (investigator assessment) were reported after a follow-up period of 30 months. The corresponding figures for mBCC were $7.7 \%$ and $23.1 \%$. The duration of response was 26.1 months (laBCC) and 24.0 months (mBCC). Median overall survival had not been reached in either population. Two-year survival rates were $93.2 \%$ (laBCC) and $69.3 \%$ (mBCC). No new, previously unreported adverse events had been observed.

\section{2 Immune checkpoint inhibitors}

Basal cell carcinomas are characterized by a high mutation load, caused by chronic UV exposure as a cofactor of carcinogenesis. Hence, these tumors are good candidates for immunotherapy with checkpoint inhibitors, anti-PD1 antibodies in particular. Following anecdotal reports about their therapeutic benefit in both treatment-naive as well as treatment-refractory (unsuccessfully treated with hedgehog inhibitors) patients with advanced BCC, scientific interest in this form of treatment has been steadily increasing.

A phase 2 approval study with an anti-PD1 antibody is currently being conducted in Germany (cemiplimab; REGN2810; NCT-No.: 03132636). Cemiplimab is an anti-PD1-antibody that is intended to be approved for metastatic (cohort 1) and locally advanced BCC (cohort 2). Cemiplimab is given intravenously at a dose of $350 \mathrm{mg}$ every three weeks. All patients are required to have received prior treatment with a hedgehog inhibitor approved for this indication (vismodegib or sonidegib) and a history of disease progression, lack of therapeutic response, and/or intolerance in the form of intolerable adverse events on hedgehog inhibitor therapy.

\section{3 Electrochemotherapy (ECT)}

ECT is a nonthermal method for tumor ablation. Electrical impulses given by special needle electrodes temporarily increase the permeability of cell membranes for chemotherapeutic agents, usually bleomycin (electroporation) [112]. The 
procedure is used for nonspecific treatment of advanced cancers and cutaneous metastases of a wide range of primary cancer types $[113,114]$. Epithelial tumors, such as BCC, may also be treated with this method [115]. This also includes multiple lesions in patients with basal cell carcinoma syndrome [116].

\section{Treatment of elderly patients}

Recommendation (strong consensus)
In general, treatment of BCC in elderly individuals shall
be based on the same curative goals as treatment in
younger patients. The choice of treatment shall factor in
individual aspects such as comorbidity, life expectancy,
and tumor characteristics.

More than $50 \%$ of nonmelanoma skin cancers (NMSCs) are diagnosed in patients older than 65 years of age. It is expected that the percentage of affected individuals in this age group will increase to over $70 \%$ by 2030 [117-119].

The National Institute on Aging (USA) classifies elderly individuals into three categories: the younger old (65 to 75 years), the old (76 to 85 years), and the older old (86 years or older). The demographic subgroup of the elderly, including very old individuals, shows the highest increase in the incidence of BCC. With increasing age comes a reduced resistance to external factors such as those associated with aggressive therapeutic interventions. The concept of frailty has been developed in order to better describe and understand the needs of the elderly and old population [120].

The increasing number of comorbidity associated with aging limits the therapeutic spectrum (anticoagulants, impaired kidney function). A Dutch group has established a list of goals that should be observed in the development of guidelines for the treatment of NMSC in frail, older patients [121]. Based on the results of their study, the authors recommend considering at least the following parameters during guideline development:

1. Limited life expectancy

2. Treatment goals other than curative treatment

3. Comorbidity

4. Tumor characteristics

When choosing the treatment approach, it should be considered that surgery for BCC can usually be performed under local anesthesia and frequently in an outpatient setting. Even if a skin graft is required, treatment until complete healing takes no longer than four weeks. Topical therapy too, possibly with the assistance of a caregiver, may play an important role in this patient group, given that these treatments can be carried out at home in most cases or require only outpatient contact. Radiation therapy requires a greater level of compliance, takes a longer period of time, and requires daily visits to a radiation therapy facility [122]. As systemic therapy of laB$\mathrm{CC}$ involves long-term treatment and is frequently associated with adverse events that impair patients' quality of life, it is no useful alternative to surgery in older patients.

In light of the frailty and comorbidity observed in elderly individuals, treatment may be geared towards a more personalized, individual approach than the standard course of action [123]. However, given the usually favorable ratio of therapeutic effort to benefit, the goal should always be complete tumor excision in old patients, too.

\section{Prevention}

For general information, the reader is referred to the evidence-based (S3) guidelines "Prevention of Skin Cancer". In addition, new recommendations for chemoprevention are presented herein.

Recommendations (strong consensus)
Nicotinamide ( 500 mg twice daily) may be used for the
prevention of BCC, in particular for secondary preventi-
on in patients with preexisting BCC.
Retinoids shall not be used for the prevention of BCC.

\section{1 Nicotinamide (vitamin $B_{3}$ )}

Nicotinamide may boost DNA repair mechanisms and thus counteract cellular UV damage. In the large Australian double-blind randomized controlled ONTRAC trial (Oral Nicotinamide to Reduce Actinic Cancer), nicotinamide $500 \mathrm{mg}$ twice daily was shown to reduce the risk of developing BCC by $20 \%$ in 386 patients with NMSC (95\% CI, -6-39; $\mathrm{p}=0.12$ ) [124]. Given that only patients with a history of multiple BCCs were included in the study, the drug seems to be of particular relevance for secondary prevention in this high-risk patient group. Nicotinamide in significantly lower daily doses did not reduce the incidence of BCC. Whether nicotinamide might also play a role in primary prevention is currently subject to debate [125].

\section{2 Retinoids}

Retinoids slow down the cell cycle and promote antitumor effects, thus resulting in more efficient cellular repair of UV-induced damage [126]. However, various studies have shown that this effect is only relevant for the development of squamous cell carcinoma and its precursor lesions, whereas it seems to play only a minor role for the development of BCC [127]. As retinoids are potentially associated with numerous adverse events (headache, myalgia, sicca symptoms, arthralgia, fatigue, depression, teratogenicity), their use cannot be recommended. 


\section{3 COX2 inhibitors}

Several studies suggest that pharmacological inhibition of COX2 may prevent epithelial neoplasms, and that daily use of celecoxib might reduce the risk of developing BCC [128, 129]. Similar to nicotinamide, especially high-risk patients with a history of BCC seem to benefit. However, there is insufficient evidence in the literature, and the data available is too heterogeneous to recommend this form of chemoprevention. Further large-scale clinical studies are desirable to better elucidate the significance of COX2 inhibitors in the prevention of BCC.

\section{Follow-up}

\section{Recommendation (consensus)}

Standardized follow-up of patients with basal cell carcinoma facilitates early detection of local recurrence and secondary tumors. It shall be carried out in a risk-stratified manner:

- Isolated, surgically treated BCC and low recurrence risk*: follow-up after 6 months to rule out local recurrence, then once a year.

- Multiple BCCs, high recurrence risk*, laBCC, $m B C C$, syndromes: follow-up every 3 months. If there is no new BCC or recurrence for more than 2 years, subsequent follow-up once a year. Closer follow-up may be performed in individual cases.

*For classification of recurrence risk, see chapter "Risk stratification"

\section{Recommendations (strong consensus)}

Patients shall be instructed to perform regular selfexams to detect BCC lesions as early as possible.

Patients with basal cell carcinoma - in particular those with basal cell carcinoma syndrome or chronically immunosuppressed patients - shall protect themselves against excessive sun exposure.

Given that patients with a history of BCC are at a significantly increased risk of developing another BCC, regular follow-up is indispensable. These patients are also at risk of developing other forms of skin cancer (squamous cell carcinoma and melanoma). In a meta-analysis of 45 studies, it was reported that nearly $30 \%$ of patients with BCC developed another BCC and almost $5 \%$ developed squamous cell carcinoma [130]. A prospective cohort study (2015) of 923 patients with a history of BCC revealed the five-year probability of developing another BCC to be nearly $35 \%$. That likelihood increased to $50 \%$ after ten years [131]. In their prospective case-control study, Rees et al. were able to demonstrate that the melanoma risk was also increased after the initial diagno- sis of BCC (hazard ratio [HR] 3.28; CI 1.66-6.51) [132]. The risk of local recurrence depends not only on individual tumor characteristics but also on the treatment approach chosen. Patients with a prior history of local recurrence are more likely to develop yet another local recurrence. Future studies on local recurrence rates are urgently needed as our current insight is based on very old data.

Apart from regular follow-up during skin cancer screening, patients should be instructed to perform selfexams of the skin at regular intervals or to be examined by their partner/relatives, and to immediately seek medical attention if they detect a conspicuous skin lesion.

\section{Acknowledgments}

The authors thank the following societies and organizations for their involvement in the development of these guidelines: ADH, ADO, ARO, BVDD, BV Dt. Pathologen, DDG, DEGRO, DGCH, DGDC, DGMKG, DGPR ÄC, DRG, DGP, Hautkrebsnetzwerk e. V, DG HNO, DOG/ BVA, AG Onkologische Patho, ATO, ABD, ApDD, AHMO, AET. Moreover, the coordinating team would like to thank all mandate holders, experts, patient representatives, and work group members as well as the authors of the previous version of the present guideline.

\section{Conflict of interest}

Please refer to the guideline report for a complete list of the conflicts of interest and information on how they were addressed during the development of this guideline. The report is available on the AWMF website (registry number 032-021).

\section{Correspondence to}

Prof. Dr. med. Stephan Grabbe

Department of Dermatology

University Medical Center

Langenbeckstraße 1

55131 Mainz, Germany

E-mail: stephan.grabbe@unimedizin-mainz.de

\section{References}

1 Frerich B, Prall F. Basalzellkarzinom der Gesichts und Kopfhaut. Update der Therapieverfahren. MKG-Chirurg 2018; 11: 49-63.

2 Dubin N, Kopf AW. Multivariate risk score for recurrence of cutaneous basal cell carcinomas. Arch Dermatol 1983; 119: 373-7.

3 Rigel DS, Robins P, Friedman RJ. Predicting recurrence of basal-cell carcinomas treated by microscopically controlled excision: a recurrence index score. J Dermatol Oncol 1981; 7: 807-10. 
4 Bogelund FS, Philipsen PA, Gniadecki R. Factors affecting the recurrence rate of basal cell carcinoma. Acta Derm Venereol 2007; 87: 330-4.

5 Scrivener Y, Grosshans E, Cribier B. Variations of basal cell carcinomas according to gender, age, location and histopathological subtype. Br J Dermatol 2002; 147(1): 41-7.

6 NCCN Clinical Practice Guidelines in Oncology: Basal Cell Skin Cancer, J Natl Compr Canc Netw 2016; 14: 574-97.

7 Silverman MK, Kopf AW, Grin CM et al. Recurrence rates of treated basal cell carcinomas. Part 1: Overview. J Dermatol Surg Oncol 1991; 17(9): 713-8.

8 Breuninger $\mathrm{H}$, Dietz K. Prediction of subclinical tumor infiltration in basal cell carcinoma. J Dermatol Surg Oncol 1991; 17: $574-8$.

9 Rowe DE, Carroll RJ, Day CL Jr. Long-term recurrence rates in previously untreated (primary) basal cell carcinoma: implications for patient follow-up. J Dermatol Surg Oncol 1989; 15(3): 315-28 und 15: 424-31.

10 Tischendorf L. Kliniksbezogene retrospektive Studie zum Wandel von Prognose und prognostisch relevanten Faktoren operativ behandelter Mund-, Kiefer- und Gesichtstumoren zwischen 1948 und 1982. Medizinische Dissertation, MartinLuther-UniversitätHalle-Wittenberg, 1991. https://d-nb. info/1143595866/34.

11 Karagas MR, McDonald JA, Greenberg ER et al. Risk of basal cell and squamous cell skin cancers after ionizing radiation therapy. J Natl Cancer Inst 1996; 88(24): 1848-53.

12 Lichter MD, Karagas MR, Mott LA et al. Therapeutic ionizing radiation and the incidence of basal cell carcinoma and squamous cell carcinoma. Arch Dermatol 2000; 136(8): 1007-11.

13 Penn I. Cancers in renal transplant recipients. Adv Ren Replace Ther 2000; 7(2): 147-56.

14 Lott DG, Manz R, Koch C, Lorenz RR. Aggressive behavior of nonmelanotic skin cancers in solid organ transplant recipients. Transplantation 2010; 90(6): 683-7.

15 Dandurand M, Petit T, Martel P, Guillot B. Management of basal cell carcinoma in adults Clinical practice guidelines. Eur J Dermatol 2006; 16(4): 394-401.

16 Telfer NR, Colver GB, Morton CA. British Association of Dermatologists. Guidelines for the management of basal cell carcinoma. Br J Dermatol 2008; 159(1): 35-48.

17 Gulleth Y, Goldberg N, Silverman RP, Gastman BR. What is the best surgical margin for a Basal cell carcinoma: a metaanalysis of the literature. Plast Reconstr Surg 2010; 126(4): 1222-31.

18 Reinhold U, Dirschka T, Kurzen H et al. Praxisnaher Behandlungspfad Basalzellkarzinom. Der Deutsche Dermatologe 2016; 10(suppl), 1-12.

19 Trakatelli M, Morton C, Nagore E et al. Update of the European guidelines for basal cell carcinoma management. Eur J Dermatol 2014; 24: 312-29.

20 Kauvar AN, Cronin T, Roenigk R et al. Consensus for nonmelanoma skin cancer treatment: basal cell carcinoma, including a cost analysis of treatment methods. Dermatol Surg 2015; 41: 550-71.

21 Abramson AK, Krasny MJ, Goldman GD. Tangential shave removal of basal cell carcinoma. Dermatol Surg 2013; 3: 38792.
22 Venturini M, Gualdi G, Zanca A et al. A new approach for presurgical margin assessment by reflectance confocal microscopy of basal cell carcinoma. Br J Dermatol 2016; 174: 380-5.

23 Nahhas AF, Scarbrough CA, Trotter S. A Review of the Global Guidelines on Surgical Margins for Nonmelanoma Skin Cancers. J Clin Aesthet Dermatol 2017; 10: 37-46.

24 Newlands C, Currie R, Memon A et al. Non-melanoma skin cancer: United Kingdom National Multidisciplinary Guidelines. J Laryngol Otol 2016; 130: S125-S132.

25 Ito $\mathrm{T}$, Inatomi $\mathrm{Y}$, Nagae $\mathrm{K}$ et al. Narrow-margin excision is a safe, reliable treatment for well-defined, primary pigmented basal cell carcinoma: an analysis of 288 lesions in Japan. J Eur Acad Dermatol Venereol 2015; 29(9): 1828-31.

26 Blasco-Morente G, Garrido-Colmenero C, Pérez-López I et al. Study of shrinkage of cutaneous surgical specimens. J Cutan Pathol 2015; 42: 253-7.

27 Kerns MJ, Darst MA, Olsen TG et al. Shrinkage of cutaneous specimens: formalin or other factors involved? J Cutan Pathol 2008; 35: 1093-6.

28 Masud D, Moustaki M, Staruch R, Dheansa B. Basal cell carcinomata: Risk factors for incomplete excision and results of re-excision. J Plast Reconstr Aesthet Surg 2016; 69: 652-6.

29 Bozan A, Gode S, Kaya I et al. Long-term Follow-up of Positive Surgical Margins in Basal Cell Carcinoma of the Face. Dermatol Surg 2015; 41: 761-7.

30 Borghi A, Corazza M, Ricci M et al. Basal cell carcinoma incompletely excised: a case-control study on recurrence. $G$ Ital Dermatol Venereol 2016; 151: 145-53.

31 Boulinguez S, Grison-Tabone C, Lamant L et al. Histological evolution of recurrent basal cell carcinoma and therapeutic implications for incompletely excised lesions. $\mathrm{Br}$ J Dermatol 2004; 151: 623-6.

32 Angulo J, Serra-Guillén C, Traves V et al. Mohs micrographic surgery for repeat excision of basal cell carcinomas on the head with positive margins. Actas Dermosifiliogr 2011; 102: 797-804.

33 Robinson JK, Fisher SG. Recurrent basal cell carcinoma after incomplete resection. Arch Dermatol 2000; 136: 1318-24.

34 Löser CR, Rompel R, Möhrle M et al. S1 guideline: microscopically controlled surgery (MCS). J Dtsch Dermatol Ges 2015; 13: 942-51.

35 vanLoo E, Mosterd K, Krekels GA et al. Surgical excision versus Mohs' micrographic surgery for basal cell carcinoma of the face: A randomised clinical trial with 10 year follow-up. Eur J Cancer 2014; 50(17): 3011-20.

36 Sin CW, Barua A, Cook A. Recurrence rates of periocular basal cell carcinoma following Mohs micrographic surgery: a retrospective study. Int J Dermatol 2016; 55(9): 1044-7.

37 Hoorens I, Batteauw A, Van Maele G et al. Mohs micrographic surgery for basal cell carcinoma: evaluation of the indication criteria and predictive factors for extensive subclinical spread. Br J Dermatol 2016; 174(4): 847-52.

38 Wain RA, Tehrani H. Reconstructive outcomes of Mohs surgery compared with conventional excision: A 13-month prospective study. J Plast Reconstr Aesthet Surg 2015; 68(7): 946-52.

39 Lubeek SF, Arnold WP. A retrospective study on the effectiveness of curettage and electrodesiccation for clinically 
suspected primary nodular basal cell carcinoma. $\mathrm{Br}$ J Dermatol 2016; 175: 1097-8.

40 Samain A, Boullié MC, Duval-Modeste AB, Joly P. Cryosurgery and curettage-cryosurgery for basal cell carcinomas of the mid-face. J Eur Acad Dermatol Venereol 2015; 29: 1291-6.

41 Kakkassery V, Loeffler KU, Sand M et al. Current diagnostics and therapy recommendations for ocular basal cell carcinoma. Ophthalmologe 2017; 114(3): 224-36.

42 Lohuis PJ, Joshi A, Borggreven PA et al. Aggressive basal cell carcinoma of the head and neck: challenges in surgical management. Eur Arch Otorhinolaryngol 2016; 273: 3881-9.

43 Veness MJ, Chong L, Tiver K, Gebski V. Basal cell carcinoma of the nose: an Australian and New Zealand radiation oncology patterns-of-practice study. J Med Imaging Radiat Oncol 2008; 52: 382-93.

44 Bhatnagar A, Patel R, Werschler WP et al. High-dose Rate Electronic Brachytherapy: A Nonsurgical Treatment Alternative for Nonmelanoma Skin Cancer. J Clin Aesthet Dermatol 2016; 9(11): 16-22.

45 Valeriani M, Nicosia L, Agolli L et al. Mono- and Bi-weekly Hypofractionated Radiation Therapy for the Treatment of Epithelial Skin Cancer in Very Elderly Patients. Anticancer Res 2017; 37(2): 825-30.

46 Piccinno R, Benardon S, Gaiani FM et al. Dermatologic radiotherapy in the treatment of extensive basal cell carcinomas: a retrospective study. J Dermatolog Treat 2017; 28(5): 426-30.

47 Delishaj D, Rembielak A, Manfredi B et al. Non-melanoma skin cancer treated with high-dose-rate brachytherapy: a review of literature. J Contemp Brachytherapy 2016; 8(6): 533-40.

48 Ballester-Sánchez R, Pons-Llanas O, Candela-Juan C et al. Electronic brachytherapy for superficial and nodular basal cell carcinoma: a report of two prospective pilot trials using different doses. J Contemp Brachytherapy 2016; 8(1): 48-55.

49 Duinkerken CW, Lohuis PJ, Heemsbergen WD et al. Orthovoltage for basal cell carcinoma of the head and neck: Excellent local control and low toxicity profile. Laryngoscope 2016; 126(8): 1796-802.

50 Pampena R, Palmieri T, Kyrgidis A et al. Orthovoltage radiotherapy for nonmelanoma skin cancer (NMSC): Comparison between 2 different schedules. J Am Acad Dermatol 2016; 74(2): 341-7.

51 Rishi A, Hui Huang S, O'Sullivan B et al. Outcome following radiotherapy for head and neck basal cell carcinoma with 'aggressive' features. Oral Oncol 2017; 72: 157-64.

52 Avril MF, Auperin A, Margulis A et al. Basal cell carcinoma of the face: surgery or radiotherapy? Results of a randomized study. Br J Cancer 1997; 76(1): 100-6.

53 Cho M, Gordon L, Rembielak A, Woo TC. Utility of radiotherapy for treatment of basal cell carcinoma: a review. Br J Dermatol 2014; 171(5): 968-73.

54 Olschewski T, Bajor K, Lang B et al. Radiotherapy of basal cell carcinoma of the face and head: Importance of low dose per fraction on long-term outcome. J Dtsch Dermatol Ges 2006; 4(2): 124-30.

55 Abbatucci JS, Boulier N, Laforge T, Lozier JC. Radiation therapy of skin carcinomas: results of a hypofractionated irradiation schedule in 675 cases followed more than 2 years. Radiother Oncol 1989; 14(2): 113-9.

Neville JA, Welch E, Leffell DJ. Management of nonmelanoma skin cancer in 2007. Nat Clin Pract Oncol 2007; 4(8): 462-9.

57 McKeown SR, Hatfield P, Prestwich RJ et al. Radiotherapy for benign disease; assessing the risk of radiation-induced cancer following exposure to intermediate dose radiation. $\mathrm{Br}$ J Radiol 2015; 88(1056): 20150405.

58 Preston DL, Shimizu Y, Pierce DA et al. Studies of mortality of atomic bomb survivors. Report 13: solid cancer and noncancer disease mortality: 1950-1997. 2003. Radiat Res 2012; 178(2):

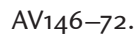

Wiltink LM, Nout RA, Fiocco M et al. No Increased Risk of Second Cancer After Radiotherapy in Patients Treated for Rectal or Endometrial Cancer in the Randomized TME, PORTEC-1, and PORTEC-2 Trials. J Clin Oncol 2015; 33(15): 1640-6.

60 Schulte KW, Lippold A, Auras C et al. Soft x-ray therapy for cutaneous basal cell and squamous cell carcinomas. I Am Acad Dermatol 2005; 53(6): 993-1001.

61 Hall VL, Leppard BJ, McGill J et al. Treatment of basal-cell carcinoma: comparison of radiotherapy and cryotherapy. Clin Radiol 1986; 37(1): 33-4.

62 Garcia-Martin E, Gil-Arribas LM, Idoipe $\mathrm{M}$ et al. Comparison of imiquimod $5 \%$ cream versus radiotherapy as treatment for eyelid basal cell carcinoma. Br J Ophthalmol 2011; 95(10): 1393-6.

63 Ratner D, Lowe L, Johnson TM, Fader DJ. Perineural spread of basal cell carcinomas treated with Mohs micrographic surgery. Cancer 2000; 88(7): 1605-13.

64 Leibovitch I, Huilgol SC, Selva D et al. Basal cell carcinoma treated with Mohs surgery in Australia III. Perineural invasion. J Am Acad Dermatol 2005; 53(3): 458-63.

65 Brown Cl, Perry AE. Incidence of perineural invasion in histologically aggressive types of basal cell carcinoma. Am J Dermatopathol 2000; 22(2): 123-5.

66 McCord MW, Mendenhall WM, Parsons JT et al. Skin cancer of the head and neck with clinical perineural invasion. Int J Radiation Oncology Biol Phys 2000; 47: 89-93.

67 Gupta A, Veness M, De'Ambrosis B et al. Management of squamous cell and basal cell carcinomas of the head and neck with perineural invasion. Australas J Dermatol 2016; 57(1): 3-13.

68 Mendenhall WM, Amdur RJ, Hinerman RW et al. Radiotherapy for cutaneous squamous and basal cell carcinomas of the head and neck. Laryngoscope 2009; 119(10): 1994-9.

69 Swanson EL, Amdur RJ, Mendenhall WM et al. Radiotherapy for basal cell carcinoma of the medial canthus region. Laryngoscope 2009; 119(12): 2366-8.

70 Geisse J, Caro I, Lindholm J et al. Imiquimod $5 \%$ cream for the treatment of superficial basal cell carcinoma: results from two phase III, randomized, vehicle-controlled studies. J Am Acad Dermatol 2004; 50(5): 722-33.

71 Love E, Bernhard J, Bordeaux J. Topical imiquimod or fluorouracil therapy for basal and squamous cell carcinoma-systematic review. Arch Derm 2009; 145(12): 1431-8.

72 Bath-Hextall F, Ozolins M, Armstrong SJ et al. Surgical excision versus imiquimod $5 \%$ cream for nodular and superficial basal-cell carcinoma (SINS): a multicentre, non-inferiority, randomised controlled trial. Lancet Oncol 2014; 15: 96-105. 
73 Williams HC, Bath-Hextall F, Ozolins M et al. Surgery versus 5 \% Imiquimod for Nodular and Superficial Basal Cell Carcinoma: 5-Year Results of the SINS Randomized Controlled Trial. J Invest Dermatol 2017; 137: 614e619.

74 Roozeboom MH, Arits AH, Mosterd K et al. Three-Year FollowUp Results of Photodynamic Therapy vs. Imiquimod vs. Fluorouracil for Treatment of Superficial Basal Cell Carcinoma: A Single-Blind, Noninferiority, Randomized Controlled Trial. J Invest Dermatol 2016; 136(8): 1568-74.

75 Arits AH, Mosterd K, Essers BA et al. Photodynamic therapy versus topical imiquimod versus topical fluorouracil for treatment of superficial basal-cell carcinoma: a single blind, non-inferiority, randomised controlled trial. Lancet Oncol 2013; 14(7): 647-54.

76 Metterle L, Nelson C, Patel N. Intralesional 5-fluorouracil (FU) as a treatment for nonmelanoma skin cancer (NMSC): A review. J Am Acad Dermatol 2016; 74: 552-7.

77 Ramsay JR, Suhrbier A, Aylward JH et al. The sap from Euphorbia peplus is effective against human nonmelanoma skin cancers. Br J Dermatol 2011; 164(3): 633-6.

78 Siller $\mathrm{G}$, Rosen R, Freeman $\mathrm{M}$ et al. PEPoo5 (ingenolmebutate) gel for the topical treatment of superficial basal cell carcinoma: results of a randomized phase Ila trial. Australas J Dermatol 2010; 51(2): 99-105.

79 Brinkhuizen T, Frencken KJA, Nelemans PJ et al. The effect of topical diclofenac $3 \%$ and calcitriol $3 \mathrm{mg} / \mathrm{g}$ on superficial basal cell carcinoma (sBZK) and nodular basal cell carcinoma (nBZK): A phase II, randomized controlled trial. J Am Acad Dermatol 2016; 75(1): 126-34.

80 Basset-Seguin N, Ibbotson SH, Emtestam L. Topical methyl aminolaevulinate photodynamic therapy versus cryotherapy for superficial basal cell carcinoma: a 5 year randomized trial. Eur J Dermatol 2008; 18: 547-53.

81 Szeimies RM, Ibbotson S, Murrell DF. A clinical study comparing methyl aminolevulinate photodynamic therapy and surgery in small superficial basal cell carcinoma (8-20 $\mathrm{mm}$ ), with a 12-month follow-up. JEADV 2008; 22: 1302-11.

82 Peng Q, Warloe T, Berg K et al. 5-Aminolevulinic acid-based photodynamic therapy. Clinical research and future challenges. Cancer 1997; 79: 2282-308.

83 Kessels J, Hendriks J, Nelemans P et al. Two-fold illumination in topical 5-aminolevulinic acid (ALA)-mediated photodynamic therapy (PDT) for superficial basal cell carcinoma (sBZK): A retrospective case series and cohort study. J Am Acad Dermatol 2016; 74(5): 899-906.

84 Rhodes LE, de Rie M, Enstrom Y et al. Photodynamic therapy using topical methyl aminolevulinate vs surgery for nodular basal cell carcinoma: results of a multicenter randomized prospective trial. Arch Dermatol 2004; 140: 17-23.

85 Rhodes LE, de Rie MA, Leifsdottir R et al. Five-year follow-up of a randomized prospective trial of topical methyl aminolevulinate-photodynamic therapy versus surgery for nodular basal cell carcinoma. Arch Dermatol 2007; 143: 1131-6.

86 Fantini F, Greco A, Del Giovane P et al. Photodynamic therapy for basal cell carcinoma: clinical and pathological determinants of response. JEADV 2011; 25: 896-901.

87 Zou Y, Zhao Y, Yu J et al. Photodynamic therapy versus surgical excision to basal cell carcinoma: meta-analysis. Journal of Cosmetic Dermatology 2016; 15, 374-82.
88 Kuijpers D, Thissen MR, Thissen CA et al. Similar effectiveness of methylaminolevulinate and 5 -aminolevulinate in topical photodynamic therapy for nodular basal cell carcinoma. J Drugs Dermatol 2006; 5: 642-5.

89 Wiegell SR, Skødt V, Wulf HC. Daylight-mediated photodynamic therapy of basal cell carcinomas - an explorative study. J Eur Acad Dermatol Venereol 2014; 28(2): 169-75.

90 Collier NJ, Ali FR, Lear JT. Efficacy of photodynamic therapy for treatment of basal cell carcinoma in organ transplant recipients. Lasers Med Sci 2015; 30(4): 1407-9.

91 Alter $\mathrm{M}$, Hillen $\mathrm{U}$, Leiter $\mathrm{U}$ et al. Current diagnosis and treatment of basal cell carcinoma. J Dtsch Dermatol Ges 2015; 13(9): 863-74.

92 Kuflik EG. Cryosurgery for skin cancer: 30-year experience and cure rates. Dermatol Surg 2004; 30: 297-30.

93 Har-Shai Y, Sommer A, Gil T et al. Intralesional cryosurgery for the treatment of basal cell carcinoma of the lower extremities in elderly subjects: a feasibility study. Int J Dermatol 2016; 55: 342-50.

94 Sierra H, Damanpour S, Hibler B et al. Confocal Imaging of Carbon Dioxide Laser-Ablated Basal Cell Carcinomas: An Ex-Vivo Study on the Uptake of Contrast Agent and Ablation Parameters. Lasers Surg Med 2016; 48(2): 133-9.

95 Yung DS, Cho HH, Ko HC et al. Recurrent basal cell carcinoma following ablative laser procedures. J Am Acad Dermatol 2011; 64(4): 723-9.

96 Haedersdal M, Erlendsson AM, Paasch U, Anderson RR. Translational medicine in the field of ablative fractional laser (AFXL)assisted drug delivery: A critical review from basics to current clinical status. J Am Acad Dermatol 2016; 74(5): 981-1004.

97 Nguyen BT, Gan SD, Konnikov N, Liang CA. Treatment of superficial basal cell carcinoma and squamous cell carcinoma in situ on the trunk and extremities with ablative fractional laserassisted delivery of topical fluorouracil. J Am Acad Dermatol 2015; 72(3): 558-60.

98 Karsai S, Friedl H, Buhck $\mathrm{H}$ et al. The role of the 595-nm pulsed dye laser in treating superficial basal cell carcinoma: outcome of a double-blind randomized placebo-controlled trial. $\mathrm{Br}$ J Dermatol 2015; 172: 677-83.

99 Ortiz AE, Anderson RR, Avram MM. 1064nm Long-Pulsed Nd: YAG Laser Treatment of Basal Cell Carcinoma. Lasers Surg Med 2015; 47: 106-10.

100 Ortiz AE, Anderson RR, DiGiorgio C et al. An expanded study of long-pulsed $1064 \mathrm{~nm} \mathrm{Nd:} \mathrm{YAG} \mathrm{laser} \mathrm{treatment} \mathrm{of} \mathrm{basal}$ cell carcinoma. Lasers Surg Med 2018 Feb 13. https://doi. org/10.1002/lsm.22803 [Epub ahead of print].

101 Rubin Al, Chen EH, Ratner D. Basal-cell carcinoma. N Engl J Med 2005; 353: 2262-9.

102 McCusker M, Basset-Sequin N, Dummer R et al. Metastatic basal cell carcinoma: prognosis dependent on anatomic site and spread of disease. Eur J Cancer 2014; 50: 774-83.

103 Sekulic A, Migden MR, Oro AE et al. Efficacy and safety of vismodegib in advanced basal-cell carcinoma. $N$ Engl J Med 2012; 366: 2171-9.

104 Sekulic A, Migden MR, Basset-Seguin N et al. ERIVANCE BCC Investigators. Long-term safety and efficacy of vismodegib in patients with advanced basal cell carcinoma: final update of the pivotal ERIVANCE BCC study. BMS Cancer 2017; 17: 332. 
105 Basset-Séguin N, Hauschild A, Kunstfeld R et al. Vismodegib in patients with advanced basal cell carcinoma: Primary analysis of STEVIE, an international, open-label trial. Eur J Cancer 2017; 86: $334-48$.

106 Tang JY, Mackay-Wiggan JM, Aszterbaum M et al. Inhibiting the hedgehog pathway in patients with the basal-cell nevus syndrome. N Engl J Med 2012; 366(23): 2180-8.

107 Tang JY, Ally MS, Chanana AM et al. Inhibition of the hedgehog pathway in patients with basal-cell nevus syndrome: final results from the multicentre, randomised, double-blind, placebo-controlled, phase 2 trial. Lancet Oncol 2016; 17(12): 1720-31.

108 Mohan SV, Chang J, Li S et al. Increased Risk of Cutaneous Squamous Cell Carcinoma After Vismodegib Therapy for Basal Cell Carcinoma. JAMA Dermatol 2016; 152(5): 527-32.

109 Atwood SX, Sarin KY, Whitson RJ et al. Smoothened variants explain the majority of drug resistance in basal cell carcinoma. Cancer Cell 2015; 27(3): 342-53.

110 Migden MR, Guminski A, Gutzmer R et al. Treatment with two different doses of sonidegib in patients with locally advanced or metastatic basal cell carcinoma (BOLT): a multicentre, randomised, double-blind phase 2 trial. Lancet Oncol 2015; 16: 716-28.

111 Lear JT, Migden MR, Lewis KD et al. Long-term efficacy and safety of sonidegib in patients with locally advanced and metastatic basal cell carcinoma: 30-month analysis of the randomized phase 2 bolt study. J Eur Acad Dermatol Venereol 2018; 32(3): 372-81.

112 Reinhold U. Electrochemotherapy for primary skin cancer and skin metastasis related to other malignancies. Anticancer Drugs 2011; 22(8): 711-8.

113 Kreuter A, van Eijk T, Lehmann P et al. Electrochemotherapy in advanced skin tumors and cutaneous metastases - a retrospective multicenter analysis. J Dtsch Dermatol Ges 2015; 13(4): 308-15.

114 Bourke MG, Salwa SP, Sadadcharam M et al. Effective treatment of intractable cutaneous metastases of breast cancer with electrochemotherapy: Ten-year audit of single centre experience. Breast Cancer Res Treat 2017; 161(2): 289-97.

115 Campana LG, Testori A, Curatolo P et al. Treatment efficacy with electrochemotherapy: A multi-institutional prospective observational study on 376 patients with superficial tumors. Eur J Surg Oncol 2016; 42(12): 1914-23.

116 Kis E, Baltás E, Kinyó A et al. Successful treatment of multiple basaliomas with bleomycin-based electrochemotherapy: a case series of three patients with Gorlin-Goltz syndrome. Acta Derm Venereol 2012; 92(6): 648-51.

117 Rogers HW, Weinstock MA, Feldman SR, Coldiron BM. Incidence Estimate of Nonmelanoma Skin Cancer (Keratinocyte Carcinomas) in the U.S. Population, 2012. JAMA Dermatol 2015; 151: 1081-6.
118 Balducci L. Epidemiology of cancer and aging. J Oncol Manag 2005; 14: 47-50.

119 Garcovich S, Colloca G, Sollena P et al. Skin Cancer Epidemics in the Elderly as An Emerging Issue in Geriatric Oncology. Aging Dis 2017; 8(5): 643-61.

120 Colloca G, Corsonello A, Marzetti E et al. Treating cancer in older and oldest old patients. Curr Pharm Des 2015, 21: 1699705 .

121 Lubeek SFK, Borgonjen RJ, van Vugt LJ. Improving the applicability of guidelines on nonmelanoma skin cancer in frail older adults: a multidisciplinary expert consensus and systematic review of current guidelines. $\mathrm{Br}$ J Dermatol 2016; 175: 1003-10.

122 Veness MJ. The important role of radiotherapy in patients with non-melanoma skin cancer and other cutaneous entities. J Med Imaging Radiat Oncol 2008; 52: 278-86.

123 Amin MB, Greene FL, Edge SB et al. The Eighth Edition AJCC Cancer Staging Manual: Continuing to build a bridge from a population-based to a more "personalized" approach to cancer staging. CA Cancer J Clin 2017; 67(2): 93-9.

124 Chen AC, Martin AJ, Choy B et al. A Phase 3 Randomized Trial of Nicotinamide for Skin-Cancer Chemoprevention. N Engl J Med 2015; 373: 1618-261.

125 Park SM, Li T, Wu S et al. Niacin intake and risk of skin cancer in US women and men. Int J Cancer 2017; 140: 2023-31.

126 Amann PM, Merk HF, Baron JF. Retinoide in der Dermatopharmakologie. Hautarzt 2014; 65: 98-105.

127 Kadakia KC, Barton DL, Loprinzi CL et al. Randomized Controlled Trial of Acitretin Versus Placebo in Patients at High Risk for Basal Cell or Squamous Cell Carcinoma of the Skin (North Central Cancer Treatment Group Study 969251). Cancer 2012; 118(8): 2128-37.

128 Elmets CA, Viner JL, Pentland AP et al. Chemoprevention of Nonmelanoma Skin Cancer with Celecoxib: A Randomized, Double-Blind, Placebo-Controlled Trial. J Natl Cancer Inst 2010; 102: 1835-44.

129 Muranushi C, Olsen CM, Green AC, Pandeya N. Can oral nonsteroidal antiinflammatory drugs play a role in the prevention of basal cell carcinoma? A systematic review and metaanalysis. J Am Acad Dermatol 2016; 74: 108-19.

130 Flohil SC, van der Leest RJ, Arends LR et al. Risk of subsequent cutaneous malignancy in patients with prior keratinocyte carcinoma: a systematic review and meta-analysis. Eur J Cancer 2013; 49(10): 2365-75.

131 Wehner MR, Linos E, Parvataneni R et al. Timing of subsequent 962 new tumors in patients who present with basal cell carcinoma or cutaneous squamous cell 963 carcinoma. JAMA Dermatol 2015; 151(4): 382-8.

132 Rees JR, Zens MS, Gui J et al. Non melanoma skin cancer and subsequent cancer risk. PLoS One 2014; 9(6): e99674. 